\title{
REFLEXÕES SOBRE A TRADUÇÃO DE SI: UGO FOSCOLO E JACOPO ORTIS ENTRE A VIDA E A POIESIS
}

\section{UGO FOSCOLO AND JACOPO ORTIS BETWEEN THE LIFE AND THE POIESIS: REFLECTIONS ABOUT THE SELF-TRANSLATION}

\author{
Karine Simoni \\ Universidade Federal de Santa Catarina \\ Florianópolis, Santa Catarina, Brasil
}

RESUMO: $O$ artigo objetiva analisar a interconexão entre a escrita de si e a tradução de si a partir da experiência de Ugo Foscolo (1778-1827), autor do romance Ultime lettere di Jacopo Ortis [As últimas cartas de Jacopo Ortis], publicado em definitivo em 1817. Toma-se como corpus o referido romance e as cartas que Foscolo enviou à Antonietta Fagnani Arese entre 1801 e 1803, período que coincide com a primeira publicação completa de Ultime Lettere di Jacopo Ortis. Uma leitura comparativa entre as cartas trocadas entre Foscolo e Arese e as cartas escritas pelo personagem Jacopo Ortis e endereçadas a Lorenzo Alderani revela pontos em comum na escrita de Foscolo e do protagonista do seu romance. Utiliza-se o conceito de autor implícito de Wayne Booth (1980) e as considerações sobre tradução em Marco Lucchesi (2016).

PALAVRAS-CHAVE: Escrita de si; Tradução de si; Ugo Foscolo; Jacopo Ortis; Autor implícito

ABSTRACT: This article aims to consider the interconnections between the self-writing and the selftranslation which is focused on Ugo Foscolo's experiences (1778-1827). The objective of this study is to analyze the relation between the author Ugo Foscolo and his character Jacopo Ortis from the novel published in 1817 called Ultime lettere di Jacopo Ortis [The last letters of Jacopo Ortis]. It is taken as a corpus the said novel and the letters that Foscolo sent to Antonietta Fagnani Arese between 1801 and 1803. The first complete version of the novel Ultime Lettere di Jacopo Ortis was published during this period. Furthermore, a comparative reading reveals characteristics in common in the writing of Foscolo and the protagonist of his novel. This conclusion is based on the exchange of letters 
between Foscolo and Arese and the letters written by Jacopo Ortis and addressed to Lorenzo Alderani. For this contrast it was used the implied author concept of Wayne Booth (1980) and the considerations about translation described by Marco Lucchesi (2016)

KEYWORDS: Self-writing; Self-translation; Ugo Foscolo; Jacopo Ortis; Implied author 
A escrita de si esteja ela em uma poesia, um romance ou um epistolário, parece não refletir o ser humano real, mas sim a imagem que o autor quer oferecer de si mesmo. As fronteiras entre o ser real e o personagem são muitas vezes tão tênues a ponto de impedir tanto o leitor como o crítico de estabelecerem uma linha divisória precisa entre a vida e a poiesis. Em termos conceituais, pode ser útil retomar as considerações que Wayne Booth formulou a respeito do autor implícito. Para o crítico, "Enquanto escreve, o autor não cria, simplesmente, um 'homem em geral', impessoal, ideal, mas sim uma versão implícita de 'si próprio" (1980, p. 88), levada a cabo pela linguagem, no dizer de Roland Barthes, para quem a literatura "encena a linguagem, em vez de simplesmente utilizá-la" (2013, p. 20). O saber é evidenciado pela flexibilidade da linguagem, o que ela contrapõe não é "o real e a fantasia, a objetividade e a subjetividade, o Verdadeiro e o Belo, mas somente lugares diferentes de fala". (2013, p. 20) O autor implícito está, portanto, em uma posição interposta, que, embora criada pela narrativa dentro dos meandros da ficção, não é imparcial e não deixa de estabelecer conexões com a visão de mundo do "autor real". Dito de outra maneira, na obra de ficção o "autor real" não propriamente deixa de existir: cria/desenvolve o autor implícito e o sujeito narrante, para enfim usá-los como máscaras que o representem. (BOOTH, 1980, p. 167)

Esse é o caso do poeta, prosador, tradutor e crítico literário Ugo Foscolo (1778-1827), que, segundo Guido Bezzola, "não sabia ir muito além de si mesmo ou das próprias projeções heroicas no momento de criar seus personagens" (2006, p. 10). Opinião semelhante fora anteriormente compartilhada por Claudio Varese, ao afirmar que

Desde o Ortis, desde os primeiros sonetos autobiográficos, até os momentos extremos e difíceis da sua vida, Foscolo com frequência parou para olhar-se e definir-se. Era uma necessidade de assegurar-se da própria identidade e de contrapô-la como desafio aos homens, à sociedade, aos tempos. ${ }^{2}(1979$, p. 7)

quase como se necessitasse conferir de tempos em tempos a própria identidade de homem e de escritor, para poder contrastá-la com o mundo. Falar de si, definir-se, descrever-se, narrar-se, parecem, para ele, uma espécie de obsessão, que o induzem a usar as máscaras dos seus personagens Jacopo Ortis, Lorenzo, Didimo, Yorick e Lauretta. Segundo Francesco Flora, mais do que nos personagens, é nas cartas onde se encontra "boa parte da sua mais solitária alma, e do seu pensamento, e da lírica mais secreta; aqui, mais do que no retrato Solcataho fronte, ele revela a sua alma fulgurante e dolorida". 3 (1959, p. 29)

\footnotetext{
1 "Foscolo non sapeva andare molto al di là di se stesso o delle proprie proiezioni eroiche, nel momento di creare dei personaggi." Todas as traduções são de autoria própria

2 "Dall'Ortis, dai primi sonetti autobiografici, sino ai momenti estremi e difficili della sua vita, Il Foscolo si è fermato spesso a guardarsi e a definirsi. Era un bisogno di assicurarsi della própria identità e di contrapporla come sfida agli uomini, alla società, ai tempi."

3 "tanta parte della sua più romita anima, e del suo pensiero, e dalla più segreta lirica; qui, meglio che nel ritratto Solcataho fronte, egli svela la sua anima folgorante e mesta."
} 
A partir dessas considerações, este artigo empenha-se em analisar a relação entre o autor Ugo Foscolo e seu personagem Jacopo Ortis. A relação entre autor e personagem é entendida aqui como transposição/intersecção/diálogo entre os dois, tal qual acontece no movimento tradutório. Penso a tradução, aqui, como transposição de camadas, mistura, como o ir e vir de si para o outro, como um processo "operando com nuances e potencialidades", que enfrenta "névoa densa, com visibilidade intermitente, como um castelo de cartas, sensível aos ventos da linguagem", como refere Marco Lucchesi (2016, p. 99). Se o trabalho de tradução está envolto na névoa, o pensar sobre a tradução, por conseguinte, também precisa aceitar a condição de existir em contornos não totalmente definidos. Por isso, ao invés de apresentar aqui conclusões demasiado precisas, mostrarei um texto e um pensamento em movimento, entre as cartas de amor do epistolário de Ugo Foscolo e cartas de amor escritas pelo personagem Jacopo Ortis no romance epistolar Últimas cartas de Jacopo Ortis, ${ }^{4}$ publicado em definitivo em 1817. ${ }^{5}$ Busco entender, ou perceber, os momentos em que Foscolo se traduz em Ortis, ou vice-versa, como uma auto tradução. Essa ideia, ou percepção, surgiu da leitura das obras - epistolário e romance - e da constatação das semelhanças de forma e conteúdo entre algumas cartas, o que me leva a pensar em Foscolo como tradutor de si.

Foscolo, conhecido pela vida pouco convencional que o levou a diferentes exílios ao longo da sua vida, ${ }^{6}$ viveu vários romances, muitos deles, ou ao menos

${ }^{4}$ A trama do romance se desenrola entre outubro de 1797 e março de 1799. O protagonista Jacopo Ortis narra a sua história através de cartas enviadas ao amigo Lorenzo Alderani. Jovem veneziano de boa família, estudante e patriota jacobino, Jacopo deixa Veneza depois do Tratado de Campofórmio, através do qual Napoleão, então imperador da Itália, entrega Veneza à Áustria. Crítico da política francesa, Jacopo é perseguido e, para escapar dos seus algozes, refugia-se nas Colinas Eugâneas, ao sul de Pádua, onde conhece a família do Senhor T., pai da bela jovem Teresa, por quem se apaixona. Teresa corresponde, mas está comprometida com o nobre Odoardo, motivo pelo qual Jacopo, desiludido, vai embora e viaja por algumas cidades italianas, como Florença, Milão e Ravena. Por fim, retorna à casa do Senhor T. e, ao saber do casamento de Odoardo e Teresa, desfere um golpe de punhal contra o próprio peito na madrugada de 25 de março de 1799.

${ }^{5}$ A escrita do romance estendeu-se por quase vinte anos: em 1796, no seu Piano di Studi [Plano de estudos], Foscolo assinala a intenção de escrever um romance cujo tema seria a paixão que nutria por uma jovem de nome Isabella TeotochiAlbrizzi. Em 1798, Foscolo entrega os manuscritos a um editor de Bolonha, que por sua vez publica o texto com algumas modificações e com o título Vera storia di due amanti infelici [A verdadeira história de dois amantes infelizes], edição esta condenada por Foscolo. A primeira edição aprovada pelo autor é publicada em 1802, em Milão, e destaca, sobretudo, o tema da paixão política, enquanto as edições sucessivas de 1816, quando Foscolo estava exilado em Zurique, e de 1817, durante o exílio em Londres, são acrescidas de cartas e o tema da paixão amorosa se faz presente junto ao tema político. (FOSCOLO, 1997, p. 267)

${ }^{6}$ Nascido em Zaquintos (Grécia), filho de mãe grega e pai veneziano, migrou para a Itália ainda adolescente, estabelecendo-se em Veneza, importante centro cultural do período. Viveu, portanto, a sua juventude durante os anos do governo napoleônico na 
os documentados, com mulheres letradas, pertencentes à nobreza ou à burguesia, de boa condição social. Guido Bezzola afirma que as relações amorosas de Foscolo

tinham também uma função criadora e estimulante, da qual as cartas são um testemunho parcial sim, mas muito grande, terminando em muitos casos por atingir um notável valor artístico absoluto. ${ }^{7}$ (2006, p. 17).

O crítico ainda destaca que os personagens foscolianos - Ortis, Didimo presidem as cartas de cada uma das mulheres com quem o autor se relacionou: enquanto Didimo está presente nas cartas trocadas com Marzia Martinengo, Ortis é figura constante nas cartas enviadas à Antonietta Fagnani Arese (2006, p. 15).

As cartas que atestam a relação entre Foscolo e Antonietta Fagnani Arese (1778-1847) datam de 1801 a 1803, embora não seja possível identificar o dia e o ano precisos. É justamente nesse período, em 1802, que se dá a primeira publicação completa de Ultime Lettere di Jacopo Ortis, e uma leitura comparativa entre as cartas trocadas entre Foscolo e Arese e as cartas escritas pelo personagem Jacopo Ortis e endereçadas a Lorenzo Alderani revela pontos em comum na escrita de Foscolo e do protagonista do seu romance.

O turbulento convívio entre Foscolo e Arese, casada com o marquês lombardo Marco Arese Lucini, é conhecido pelas 134 cartas que Foscolo endereçou à jovem e que foram devolvidas a ele quando Foscolo descobriu uma traição e o envolvimento amoroso terminou. Nessas cartas é possível visualizar a força emotiva, a variedade de tons e a capacidade foscoliana de criação artística da própria imagem: com efeito, em vários momentos Foscolo se intitula "Ortis". É o caso, para citar um exemplo, de um trecho da carta 22 do epistolário Lettere d'amore, em que Foscolo escreve: "Se você, ao receber essa carta amassou-a para escondê-la... você fez mal. Há dentro dela o perfil de Ortis: ali se poderá ver o contorno de Ugo Foscolo, e a fisionomia de São Luís." ${ }^{.8}$ (FOSCOLO, 2006, p. 76)

Itália e não esteve imune aos acontecimentos políticos do seu tempo, mostrando-se inicialmente admirador de Napoleão, visto como a esperança de unificação da Itália, para depois transformar-se em um severo crítico da sua administração. Estreou como literato em 1795, com a representação da tragédia Tieste em Veneza, que lhe deu fama e reconhecimento do público. Porém, a vida desregrada, aliada às desavenças políticas e literárias, o compeliu a uma longa e contínua experiência de exílio até a sua morte, ocorrida em 1827, em Londres. Para o estudo detalhado da vida e da obra do autor recomendo NICOLETTI, Giuseppe. Foscolo. Roma: Salerno Editrice, 2006; TERZOLI, Maria Antonietta. Com l'incantesimodella parola: Foscolo scrittore e critico. Roma: Edizioni di Storia e Letteratura, 2007; VERDENELLI, Marcello. Foscolo: una modernità al plurale. Roma: Anemone Purpurea, 2007.

7 "avevano anche una funzione creativa e stimolatrice, di cui lelettere sono testemonianza parziale si ma molto alta, finendo in parecchi casi per raggiungere un notevolissimo valore artisticoassoluto."

8 "Se tu ricevendo questa lettera l'hai strofinata per nasconderla... hai fatto male. C'è dentro il profilo dell'Ortis: ci vedrai il contorno di Ugo Foscolo, e la fisionomia di San Luigi. - Addio intanto... Il te comincia a diventar freddo. Addio." 
É válido lembrar que no século XIX a escrita epistolar é uma prática cotidiana comum a homens e mulheres de diferentes classes sociais. Nesse período, há uma melhoria no serviço postal e a carta se torna um meio de comunicação rápido. De um lado, a carta tem a função prática de transmitir notícias e de ser uma espécie de "conversação à distância", um instrumento para consolidar relações e amizades; de outro, contém informações sobre o eu e sobre as suas múltiplas confidências: estado de saúde, ideias, sentimentos, atividades. O que não quer dizer que o conteúdo das cartas deva ser tomado como "verdade", ou como fatos realmente acontecidos: se o passado é, antes de tudo, "um relato, e o que se denomina explicação não é mais que a maneira de a narração se organizar em uma trama compreensível" (VEYNE, 1998, p. 27), entendo o conteúdo das cartas de Foscolo não como fatos acontecidos, mas como representações discursivas do passado, como formas de conduta e como construções da imagem, ou imagens, que o autor buscava para si e para o mundo.

A ideia de continuum entre vida (real) e literatura (ficção) é visível em diversas cartas que Foscolo endereçou à Arese, nas quais estão afirmações como "talvez eu seja assim porque a minha vida é um contínuo romance."" (FOSCOLO, 2006, p. 129) e "Você me chama de romance, e talvez tenha razão, mas não sou porque quero... eu devo à natureza essa ardente imaginação e esse coração" ${ }^{\prime 10}$ (FOSCOLO, 2006, p. 66), que evidenciam a fusão entre vida e literatura em Foscolo. A minha hipótese é que foi na "tradução" de si para um ser ficcional que Foscolo construiu a sua poética.

Transcrevo a seguir exemplos que demonstram como Foscolo elabora uma identidade nas cartas, e como esse modo de ser parece ter sido formado em conjunto com o personagem Jacopo Ortis. Inicio com a carta 87 (não datada) enviada por Foscolo a Arese:

Eis que estou sempre com você: estive o dia todo em casa, e todos os meus pensamentos estão com a minha Antonietta; comecei a estudar mais de uma vez, mas me parece perdido cada momento que não seja consagrado unicamente a você, a você, amiga do meu coração. [...] É verdade... eu não posso the dar tudo, eu sou melancólico, perseguido por quem não me conhece, e muito infeliz; sim, infeliz, porque possuo um coração que me deixa a vida tempestuosa e dolorida, e que vai me conduzir ao sepulcro pelo caminho das lágrimas... é verdade; não posso the fazer feliz, mas eu te dou tudo aquilo que tenho; eu te amo, e de fato de amor extremamente porque, além de você, o que eu tenho de esperançoso e de doce nessa minha miserável vida? Tudo é loucura, minha tenra amada, tudo, infelizmente! $!^{11}$ (FOSCOLO, 2006, p. 163)

\footnotetext{
9 "forse io sono tale perché la mia vitaè un continuo romanzo."

10 "Chiamami romanzo, ed hai forse ragione, ma non lo sono per elezione... io devo alla natura questa ardente immaginazione e questo cuore."

11 "Eccomi sempre con te: sono stato tutt'oggi in casa, e tutti i miei pensieri sono com la mia Antonietta; ho incominciato a studiare più volte, ma mi pare perduto ogni momento
} 
Temas e estrutura muito semelhantes podem ser encontrados nas palavras do personagem Jacopo Ortis, em carta de 09 de fevereiro de 1798 endereçada à amada Teresa, presente na edição de $1802:^{12}$

Eis que estou sempre com você: são já cinco dias que eu não posso ver você, e todos os meus pensamentos são consagrados unicamente a você, a você consoladora do meu coração. É verdade; eu não posso lhe fazer feliz. Aquele meu Gênio, do qual lhe falo com frequência, vai me conduzir ao sepulcro pelo caminho das lágrimas. Eu não posso lhe fazer feliz... e eu dizia isso essa manhã a seu pai, que estava sentado junto à minha cama e sorria das minhas melancolias: e eu confessava a ele que, além de você, nada de esperançoso e de bom me resta nessa pobre vida. Tudo é loucura, minha doce amiga, tudo, infelizmente! $!^{13}$ (FOSCOLO, 1997, p. 48)

Nos trechos aqui transcritos, são evidentes vários elementos e expressões em comum: o início da frase, "Eis que estou sempre com você", é comum a ambos, assim como a expressão "todos os meus pensamentos são". Os momentos que o autor/personagem diz dedicar à amada são consagrados, respectivamente, à "amiga do meu coração" e à "consoladora do meu coração". Em ambos os excertos o autor/personagem lamenta o próprio fim, causado pela impossibilidade de viver o amor pleno com a amada, que o "vai me conduzir ao sepulcro pelo caminho das lágrimas".

O segundo exemplo é extraído da já citada carta 87:

che non sia secrato a te sola, a te, amica del mio cuore. [...] È vero... io non ti posso dar tutto, io sono melanconico, perseguitato da chi non mi conosce, e sommamente infelice; sì, infelice perché possedo um cuore che mi rende la vita tempestosa e dolente, e che mi condurrà al sepolcro per la via delle lagrime... è vero; non ti posso fare felice, maio ti do tutto quello che ho; io t'amo, e appunto t'amo estremamente perché, fuori di te, cosa mi resta di lusinghiero e di dolce in questa misera vita? Tutto è follia, mia tenera amante, tutto, purtroppo!"

${ }^{12}$ Nas edições de Zurique (1816) e de Londres (1817), essa carta será substituída pela carta de 17 de março. Contudo, a carta excluída da edição de 1802 consta em nota de rodapé na página 48 da edição utilizada nessa pesquisa.

13 "Eccomi sempre con te: sono ormai cinque giorni ch'io non posso vederti, e tutti i miei pensieri sono consecrati a te sola, a te consolatrice del mio cuore. È vero; io non ti posso fare felice. Quel mio Genio, di cui spesso ti parlo, mi condurrà al sepolcro per la via delle lagrime. Io non posso farti felice... e lo diceva stamattina a tuo padre, che se deapresso al mio letto e sorrideva delle mie malinconie: ed io gli confessava, che fuori di te nulla di lusinghiero, e di caro mi resta in questa povera vita. Tutto è follia, mia dolce amica; tutto purtroppo!" 
e quando também o suave sonho dos nossos amores terminará, acredite em mim, eu farei cair o pano; a glória, o saber, a amizade, as riquezas, todos os fantasmas que até agora recitaram na minha comédia, não servem mais para mim. Deixarei cair o pano, e deixarei que os homens se esforcem para fugir das dores de uma existência que não sabem deixar. ${ }^{14}$ (FOSCOLO, 2006, p. 163-164)

As mesmas ideias e palavras podem ser lidas no seguinte trecho da carta de 17 março de 1798 do romance Ultime lettere de Jacopo Ortis:

E quando também este meu novo e suave sonho terminar, farei de bom grado cair o pano. A glória, o saber, a juventude, as riquezas, a pátria, todos os fantasmas que até agora representaram na minha comédia já não servem para mim. Deixarei o pano cair e permitirei que os outros mortais se esforcem para aumentar os prazeres e diminuir as dores de uma vida que a cada minuto se abrevia e que até aqueles mesquinhos gostariam de convencer-se que é imortal. ${ }^{15}$ (FOSCOLO, 1997, p. 55)

Também neste exemplo se sobrepõe forma e conteúdo, e é bastante evidente a intersecção de identidades entre autor e personagem, o que resulta, como dito anteriormente, no híbrido autor-implícito, que também pode ser percebido na comparação entre os exemplos que seguem. Em cada exemplo, a primeira frase corresponde ao epistolário Lettere d'amore (2006), enquanto a segunda frase foi retirada de Ultime Lettere di Jacopo Ortis (1997):

E não tenho do que me louvar, nem do Céu, nem dos homens. ${ }^{16}$ (FOSCOLO, 2006, p. 130)

não terei do que me louvar, nem dos antigos, nem dos modernos, nem de eu mesmo ${ }^{17}$ (FOSCOLO, 1997, p. 09)

Reconhecedor dos benefícios, sou muito reconhecedor também das injúrias. ${ }^{18}$ (FOSCOLO, 2006, p. 231)

\footnotetext{
14 “e quando anche il soave sogno de' nostri amori terminerà, credimi, io calerò Il sipario; la gloria, Il sapere, l'amicizia, le ricchezze, tutti fantasmi che hanno recitato fino ad ora nella mia commedia, non fanno più per me. Io calerò il sipario, e lascerò che gli uomini si affannino per fuggire i dolori di un'esistenza che non sanno troncare".

15 "Né io vivo se non per lei sola: e quando anche questo mio nuovo sogno soave terminerà, io calerò volentieri il sipario. la gloria, il sapere, la gioventù, le ricchezze, la patria, tutti fantasmiche hanno fino ad orre citato nella mia commedia, non fanno più per me. Calerò il sipario; e lascierò che gli altri mortali s'affannino per accrescere i piaceri e menomare i dolori d'una vitache ad ogni minuto s'accorcia, e che pure que' meschini se lavorrebbero per sua dere immortale".

16 "e non ho a lodarmi nè del Cielo nè degli uomini."

17 "non avrò assai da lodarmi nè degli antichi, nè de' moderni, nè di me stesso."
} 
[...] reconhecedor dos benefícios, sou muito reconhecedor também das injúrias. ${ }^{19}$ (FOSCOLO, 1997, p. 36)

[...] eu rugia naquele dia como uma tigre, o teria despedaçado. ${ }^{20}$ (FOSCOLO, 2006, p. 147)

eu rugia naquele dia como um leão, e me parecia que o teria despedaçado. ${ }^{21}$ (FOSCOLO, 1997, p. 36)

[...] confortarei os meus tormentos com a celestial recordação dos pouquíssimos meses que você me amou. ${ }^{22}$ (FOSCOLO, 2006, p. 154)

[...] conceda-me que eu torne a morte desejada com a certeza que você me amou. ${ }^{23}$ (FOSCOLO, 1997, p. 109)

[...] como a vida é para mim assim grave, e tantas são as minhas desgraças, que eu a arrastarei no tédio e no pranto até quando terei uma mãe a quem a minha morte custaria lágrimas muito amargas. ${ }^{24}$ (FOSCOLO, 2006, p. 84-5)

[...] ah se eu não tivesse uma mão querida e desaventurada a quem a minha morte custaria lágrimas muito amargas! $!^{25}$ (FOSCOLO, 1997, p. 111)

Sim, deixe-me: as suas lágrimas irão me seguir até a minha sepultura. - A minha infeliz saúde, o meu destino, o meu coração, você, você... tudo conjura; e eu obedecerei a todos vocês. ${ }^{26}$ (FOSCOLO, 2006, p. 141)

18 "Riconoscente ai benefici, sono riconoscentissimo anche alle ingiurie."

19 "riconoscente de' benefici, sono riconoscentissimo anche delle ingiurie."

20 " [...] io rugiva quel giorno come una tigre; l'avrei sbranato."

21 "Io rugiva quel giorno come um leone, e mi pareva chel'avrei sbranato."

22 “conforterò i miei tormenti com la celeste rimembranza de' pochissimi mesiche tu mi hai amato"

23 "concedimi ch'io mi renda cara la morte con la certezza che tu m'hai amato"

24 “poichè la vita m'è così grave, e tante sono le mie sciagure, ch'io la strascinerò nella noia e del pianto fino che avrò una madre a cui la mia morte costerebbe amarissime lagrime."

${ }_{25}$ "ah s'io non avessi una madre cara e sventurata a cui la mia morte costerebbe amarissime lagrime!"

26 "Sì, lasciami: le tue lagrime mi seguiranno nella mia sepultura. - La mia infelice salute, la mia sorte, il mio cuore, tu, tu... tutto congiura; ed io vi obbedirò tutti." 
Nem um beijo? Nem adeus! - mas sim as tuas lágrimas irão me seguir até a minha sepultura. A minha saúde, o meu destino, o meu coração, você - você! em suma, tudo conjura, e eu obedecerei a todos vocês. ${ }^{27}$ (FOSCOLO, 1997, p. 112)

Com esses exemplos, que poderiam certamente ser ampliados, espero ter mostrado o que entendo por "tradução de si" no caso de Foscolo e Ortis. O fato de Foscolo se colocar como Ortis nas cartas enviadas à Arese, ou de repetir no romance trechos anteriormente escritos para a jovem, indica que escolhas biográficas e literárias se conectam sem que se possa estabelecer limites precisos entre ambas. Escreve ele que "Me pintei fielmente com todas as minhas loucuras no Ortis" (FOSCOLO, 2006, p. 54), e diante de tal afirmação é válido perguntar: com qual objetivo? Marcello Verdenelli destaca que Ultime Lettere di Jacopo Ortis, pela sua particular natureza de romance epistolar, de romance confissão, poderia ser visto pelo leitor como uma verdade mais abrangente, ao tomar forma em uma relação mais direta com a história e com a política $(2007$, p. 166).

Com esses exemplos espero ter mostrado uma possibilidade de reflexão entre biografia, escrita epistolar, literatura, teoria literária e tradução. A tradução pode ser considerada um movimento de ir de si para o outro e voltar para si - e Foscolo vai de si para seu personagem, e vice-versa. Pelo viés das cartas, o sujeito que escreve acaba por criar também uma espécie de literatura de si, literatura que cria, recria e traduz a si próprio, como um personagem em constante construção, quer real quer fictício, sendo as fronteiras muito tênues e habitadas pelo autor implícito. Um espaço aberto, maleável, repleto de possibilidades. Nas palavras do crítico italiano Mario Fubini,

distinguir entre os seus vícios e as suas virtudes, entre a vida prática e a poesia, não parece ser fácil mesmo hoje: ainda hoje Foscolo se apresenta a nós como um contemporâneo, que não nos pede tanto um juízo, mas uma dedicação completa, que não nos oferece uma obra concluída, facilmente separável da sua pessoa, mas um incessante tormento ao qual devemos $\operatorname{participar}^{28}(1962$, p. 77-78).

\footnotetext{
27 "Nè un bacio? Nè addio! - bensì le tue lagrime mi seguiranno nella mia sepultura. La mia salute, la mia sorte, il mio cuore, tu - tu! - insomma tutto congiura, edio vi obbedirò tutti."

28 "distinguere tra i suoi vizi e le sue virtù, tra la vita pratica e la sua poesia, sembra non facile neppure oggi: ancora oggi il Foscolo si presenta a noi come un contemporaneo, che non ci chiede tanto un giudizio, quanto una dedizione intera, che non ci offre un'opera compiuta, e facilmente isolabile dalla sua persona, ma un incessante travaglio a cui noi stessi dobbiamo partecipare."
} 


\section{REFERÊNCIAS}

BEZZOLA, Guido. "Introduzione". In: FOSCOLO, Ugo. Lettere d'amore. A cura di Guido Bezzola. Milano: Bur Rozzoli, 2006.

BOOTH, Wayne. A retórica da fiç̧ão. Trad. Maria Teresa H. Guerreiro. Lisboa: Arcádia, 1980.

FOSCOLO, Ugo. Lettere d'amore. A cura di Guido Bezzola. Milano: Bur Rozzoli, 2006.

FOSCOLO, Ugo. Ultime lettere di Jacopo Ortis. A cura di Giuseppe Nicoletti. Firenze: Giunti, 1997.

FLORA, Francesco. "La mente e l'animadi Ugo Foscolo". In: Storia della letteratura italiana, $I V$. Milano, Mondadori, 1959.

FUBINI, Mario. Ugo Foscolo. Firenze: La Nuova Italia, 1962.

LUCCHESI, Marco. Carteiro Imaterial. Rio de Janeiro: José Olympio, 2016.

VARESE, Cesare. "Introduzione a Ugo Foscolo". In: Autobiografia dele lettere. Roma: Salerno Editrice, 1979.

VERDENELLI, Marcello. Foscolo: una modernità al plurale. Roma: Anemone Purpurea, 2007.

VEYNE, Paul Marie. Como se escreve a história: Foucault revoluciona a história. Trad. Alda Baltar e Maria Auxiliadora Kneipp. Brasília: Editora Universidade de Brasília, 1998.

Karine Simoni KaSimoni@gmail.com

Recebido em: 18/9/2017

Aceito em: 25/2/2018 Publicado em Abril de 2018 